\title{
De Olho na Fonte: Trilha Interpretativa para Conservação das Nascentes
}

\author{
Layana Alves de Morais \\ Ivaneide Alves Soares da Costa
}

\begin{abstract}
RESUMO
O presente trabalho objetivou avaliar a contribuição de uma trilha interpretativa como ferramenta de educação ambiental e científica visando contribuir com a conservação de nascentes e construção de uma cidadania responsável. A trilha foi realizada na nascente do rio Maxaranguape, município de Pureza/RN, envolvendo 62 alunos, do $1^{\circ}$ ao $5^{\circ}$ ano do ensino fundamental da Escola Municipal Henrique de Oliveira Fagundes, em comemoração ao Dia Mundial do Meio Ambiente. Quatro pontos foram escolhidos na trilha, sendo relacionados temas como o ciclo da água, importância da vegetação para as nascentes, doenças de veiculação hídrica, poluição e preservação. A coleta de dados e instrumentos utilizados na pesquisa foram desenhos e entrevistas e, a partir da sua análise, antes e após a trilha, foi possível identificar uma importante contribuição da realização da trilha para a sensibilização ambiental dos alunos com relação à preservação das nascentes dos rios. Após a trilha, detectou-se nas produções de desenhos dos alunos mais elementos paisagísticos e maior relação homem e natureza, assim como nas entrevistas, a presença de um discurso mais coerente e mais sensibilidade ao meio ambiente. Com isso, acredita-se que a trilha interpretativa em um ambiental natural, como uma nascente, apresenta um potencial didático significativo para o ensino de ciências e incentiva ao exercício da cidadania consciente.
\end{abstract}

Palavras-chave: Educação ambiental. Espaços não formais de ensino. Água. Pureza/RN.

\section{With an Eye on the Source: Interpretive Trail for Conservation of Springs}

\begin{abstract}
The present work aimed to evaluate the contribution of an interpretative trail as a tool for environmental and scientific education seeking to help in the conservation of springs and the construction of responsible citizenship. The trail was carried out at the source of the Maxaranguape River, municipality of Pureza, Rio Grande do Norte (RN), Brazil, involving 62 students, from the 1st to 5th year of elementary school of the Escola Municipal Henrique de Oliveira Fagundes, in commemoration of the World Environment Day. Four points were chosen on the trail, approaching topics such as water cycle, importance of vegetation to the springs, waterborne diseases, pollution and preservation. The collection of data and instruments used in the research were drawings and
\end{abstract}

Layana Alves de Morais é mestranda da Universidade Federal do Rio Grande do Norte pelo Programa Regional de Pós-Graduação em Desenvolvimento e Meio Ambiente - PRODEMA. E-mail: layanaamorais@hotmail.com Ivaneide Alves Soares da Costa é doutora em Ecologia e Recursos Naturais. Atualmente, é professora Adjunta da Universidade Federal do Rio Grande do Norte e Coordenadora do PIBID -Biologia da UFRN - Campus Universitário, Lagoa Nova - Natal/RN. CEP 59.072-970. E-mail: iasoaresc@gmail.com Recebido para publicação em 18 jan. 2018. Aceito, após revisão, em 21 ago. 2018. DOI: https://doi.org/10.17648/acta.scientiae.v20iss5id3803.

Acta Scientiae v. 20 n. 5 p.847-862 set./out. 2018 
interviews and, from their analysis, before and after the activities, it was possible to identify an important contribution of the trail realization to the environmental awareness of the students regarding the preservation of the rivers. After the trail, students' drawings showed more landscape elements and a greater relationship between human and nature, as well as in the interviews, where a more coherent discourse and more sensitivity to the environment was observed. Thus, it is believed that the interpretative trail in a natural environment, such as a spring, presents a significant didactic potential for the teaching of sciences and encourages the exercise of conscious citizenship.

Keywords: Environmental education. Water. Informal Learning Spaces. Pureza/RN.

\section{INTRODUÇÃO}

Os ambientes não formais de ensino podem e devem ser usados no ensino formal e representam uma importante ferramenta para educação ambiental, por inserir o aluno dentro do contexto real tornando-os mais perceptivos e ativos.

A educação não formal compreende o ensino e a aprendizagem de conteúdos da educação formal em contextos e espaços não formais de ensino, que são regulamentados e possuem geralmente uma equipe técnica responsável pela execução das atividades, como museus, centro de ciências, parques ambientais, dentre outros. Além desses, existem também ambientes naturais e urbanos, que embora não sejam institucionalizados, favorecem o desenvolvimento de práticas educativas, que podem ser bem direcionadas, tendo como início e estruturação um objetivo bem definido. Em espaços abertos, pode proporcionar um maior contato dos participantes com o meio natural. Dentre as práticas educativas realizadas nesses ambientes, as trilhas podem se configurar em uma importante ferramenta utilizada para a sensibilização ambiental, como atividade educativa em espaços não formais de ensino. (Gohm, 1999; Jacobucci, 2008; Praxedes, 2009).

Sobre a caracterização de trilhas, Lima (1998) aborda que podem ser duas, a partir de normas internacionais: a trilha cênica, que geralmente compreende uma sequência paisagística e uma travessia por cenários (urbanos ou rurais), abrangendo cultura, história e paisagem. Possui um percurso de distância longa e pode ser considerada de natureza recreacional; e a trilha interpretativa, que apresenta um caráter educativo e é composta de instrumentos pedagógicos. Possui um percurso de distância curta e busca-se dinamizar a compreensão da sequência paisagística traçada.

As trilhas interpretativas, desde que sejam bem planejadas e executadas, alcançam objetivos que estão para além de sua função (Ikemoto, 2008). Por apresentarem um forte caráter educativo que se relaciona com a socialização, recreação e percepção paisagística, podem em muito contribuir para a sensibilização ambiental. Dessa forma, as trilhas interpretativas podem ser consideradas como uma importante ferramenta para a conservação de recursos ambientais.

Sendo a água um importante recurso para toda a forma de vida, é de grande relevância a compreensão de como o ser humano se relaciona com ele, tanto para consumo quanto para sua manutenção e preservação. O tema água pode e deve estar inserido no contexto educacional, seja na educação formal ou não formal, atuando na formação do cidadão consciente da sua responsabilidade socioambiental, crítico, reflexivo e atuante 
sobre o papel que ocupa no mundo, numa relação dinâmica de maneira local e globalmente, como parte de um sistema integrado, ao meio ambiente (Bacci et al. 2009).

Os Parâmetros Curriculares Nacionais (PCNs) apontam a importância da compreensão de relações que esse recurso tem, tanto com o ser humano quanto com todo o equilíbrio da biosfera (Brasil, 1997), como descrito abaixo:

As relações entre água e seres vivos, que por si só merecem vários capítulos das Ciências Naturais, posto que repor a água é condição para diferentes processos metabólicos (funcionamento bioquímico dos organismos), para processos de reprodução (em plantas, animais e outros seres vivos que dependem da disponibilidade de água para a reprodução), para a determinação do hábitat e do nicho ecológico, no caso de seres vivos aquáticos. (Brasil, 1997, p.36)

Os documentos oficiais (PCNs) abordam a importância da água em vários aspectos, se preocupando com fatores que envolvem seu papel na manutenção do seu equilíbrio, desde a sua captação, tratamento e distribuição à reposição desse recurso, com seus ciclos e seu papel na manutenção do equilíbrio ecológico (Brasil, 1997), o aspecto mais geral e complexo dessa temática que percorre todo o documento.

As nascentes dos rios estão relacionadas com a manutenção do equilíbrio hidrológico e ambiental, podendo ser consideradas como sistema ambiental essencial. Elas compreendem processos os quais abrangem desde aspectos de hidrogeologia até geomorfologia e antropologia da paisagem (Felippe, 2009). Mesmo diante da sua importância, as nascentes sofrem impactos ambientais devido à ação antrópica existente no seu entorno, os quais acabam alterando a qualidade e a quantidade da água.

Um desses sistemas está localizado no município de Pureza, cidade do Rio Grande do Norte, que apresenta um dos pontos turísticos mais conhecidos do litoral leste do estado, o "Olheiro de Pureza". Essa nascente dá origem ao rio Maxaranguape, corpo d'água importante para os pequenos fragmentos de mata atlântica presentes na cidade e região. Além disso, a nascente é um ponto de captação de água importante para a cidade, que tem grande parte de seu abastecimento provido desse afloramento. Contudo, esse rio sofre inúmeros impactos, tanto de deposição de esgoto não tratado ao longo de seu curso quanto na sua própria nascente, por meio do uso inadequado do turismo e de lazer pela população local e regional.

Os impactos causados não se refletem apenas no ecossistema, eles se difundem, causando problemas na população local. Casos de doenças de veiculação hídrica são frequentes no município (Brasil. Ministério da Saúde, 2011). Considerando a importância e a susceptibilidade que a nascente de Pureza apresenta, faz-se uma ferramenta valorosa a utilização desse espaço para desenvolver atividades de educação científica, de forma investigativa, para trabalhar questões socioambientais, relacionando com a realidade local, para uma formação de cidadãos críticos e responsáveis. 
Diante do exposto, o presente trabalho teve como objetivo identificar o potencial didático de uma trilha interpretativa realizada numa nascente para a sensibilização ambiental em relação à sua conservação.

\section{METODOLOGIA}

Realizou-se uma trilha interpretativa na nascente do rio Maxaranguape, situada no município de Pureza, estado do Rio Grande do Norte, conforme FIG. 01, denominada localmente como "Fonte de Pureza", no dia 05 de junho de 2017, em comemoração ao Dia Mundial do Meio Ambiente.

A ação foi promovida como parte do programa de extensão "Empoderamento de populações via educação", desenvolvido pela Universidade Federal do Rio Grande do Norte (UFRN) via Instituto de Medicina Tropical do Rio Grande do Norte (IMT$\mathrm{RN}$ ), Centro de Biociências (CB), Centro de Ciências da Saúde (CCS) e Centro de Educação (CE), que se encontra em desenvolvimento no local, relacionado a ações de diagnósticos de doenças endêmicas do município (hanseníase, leishmaniose e dengue, entre outras), estratégias de intervenção, educação em saúde e educação científica, aliando o conhecimento ao exercício da cidadania, por uma melhor qualidade de vida e ambiental.

A presente pesquisa foi desenvolvida com as turmas de $1^{\circ}$ ao $5^{\circ}$ ano do Ensino Fundamental, anos iniciais, da Escola Municipal Henrique de Oliveira Fagundes, Pureza/ RN. No turno matutino, foi realizada com as turmas de $3^{\circ}, 4^{\circ}$ e $5^{\circ}$ anos, com 40 alunos e faixa etária entre 7 e 15 anos. No turno vespertino, ocorreu com as turmas de $1^{\circ}$ e $2^{\circ}$ anos, com 22 alunos e faixa etária entre 5 e 7 anos. A ação contou com o importante apoio de uma equipe de alunos do curso de Ciências Biológicas, bolsistas PIBID (Programa Institucional de Bolsa de Iniciação à Docência) do Subprojeto Biologia da UFRN, outra do IMT/UFRN e a equipe da Escola Municipal Henrique de Oliveira Fagundes.

Para garantir os direitos éticos, foi aplicado um termo de consentimento livre e esclarecido, que consta de esclarecimentos dos instrumentos de análise da realização da atividade, para fins da pesquisa, garantindo o anonimato dos envolvidos e, além disso, um termo de autorização para permissão dos pais ou responsáveis para o aluno se deslocar da escola para a trilha, documentos os quais foram assinados pelos pais ou responsáveis. O estudo foi aprovado pelo Comitê de Ética em pesquisa da instituição responsável e compõe Projeto de Pesquisa sob Certificado de Apresentação para Apreciação Ética 12584513.1.3001.5577. 


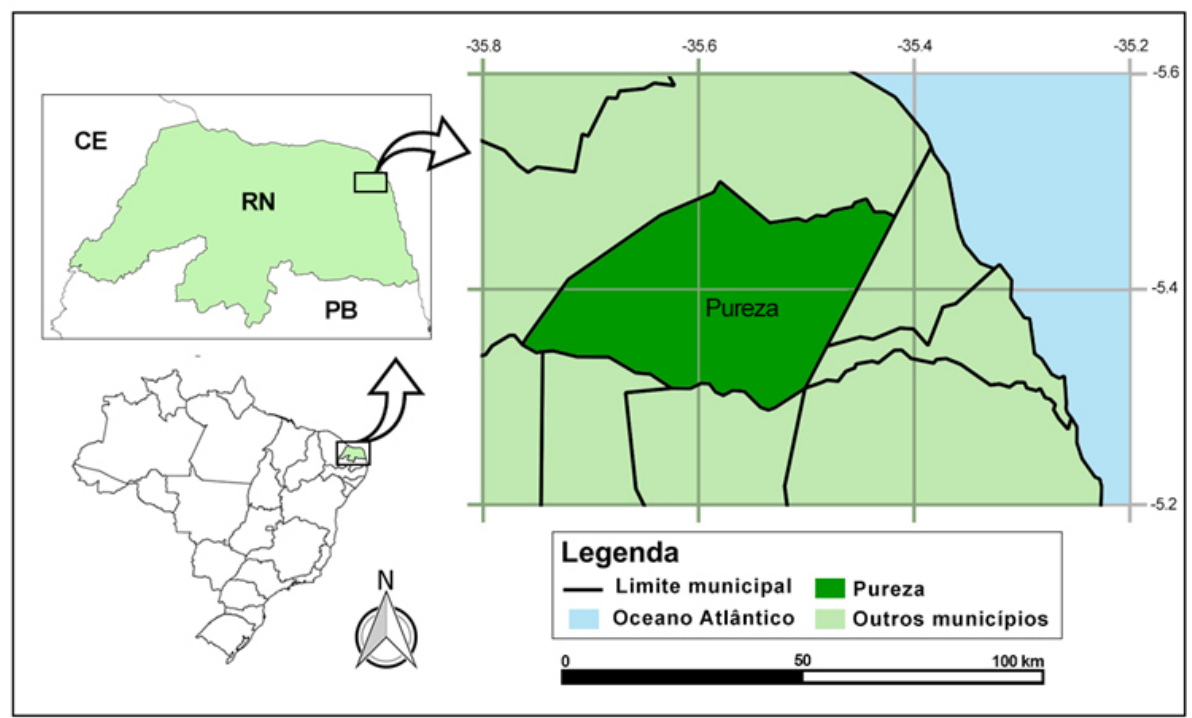

Figura 1. Localização do município de Pureza, Rio Grande do Norte.

Este estudo corresponde a uma pesquisa de natureza qualitativa, que busca compreender a problemática a partir da perspectiva do sujeito envolvido e inclui também aspectos quantitativos, contudo, apenas para descrever e sintetizar dados (Moreira, 2009).

Considerando a abordagem qualitativa desta pesquisa, tem-se como instrumentos para construção de dados, componentes que presumem o diálogo e o posicionamento dos participantes da pesquisa (Laville; Dionne, 1999). Para isso, utilizou-se a elaboração de desenho livre e a entrevista semiestruturada individual para averiguar as percepções iniciais e finais dos estudantes sobre o conceito de ambiente, água, preservação e cidadania, por meio da atribuição de valores nos aspectos conceitual, procedimental e atitudinal, expressada pelos alunos participantes da atividade, possibilitando identificar a possível sensibilização ambiental que o ambiente natural visitado pode proporcionar e contribuir para uma aprendizagem significativa, por meio de uma atividade educativa em espaço não formal de ensino. Para a realização das entrevistas, foi perguntando em cada turma quem gostaria de participar e, os alunos que se dispuseram, foram os mesmos para as entrevistas antes e depois da trilha.

Buscou-se identificar, nos desenhos de antes da trilha, como os alunos enxergavam a Fonte de Pureza e o contexto ambiental ao redor, com base no conjunto de elementos expressados. Foram agrupados nas seguintes categorias: 1) Elementos físico-químicos, fauna e flora, a qual corresponde à expressão dos elementos de água, rochas, solo, plantas e animais; 2) Elementos físico-químicos e flora, a qual se trata dos elementos de água, rochas, solo e plantas; 3) Elementos físico-químicos e fauna, a qual se refere aos elementos 
de água, rochas, solo e animais; 4) Elementos físico-químicos, a qual compreende os elementos de água, rochas e solo.

Nos desenhos após a trilha, verificou-se na expressão dos alunos a presença de elementos paisagísticos adicionais, de acordo com o objetivo da atividade e o contexto trabalhado na trilha, os quais não se encontravam no desenho antes da trilha. Foram atribuídas cinco categorias, para enquadrar o perfil dos desenhos, conforme descritas a seguir: 1) Sem adição de novos elementos paisagísticos, mas com representatividade; 2) Sem adição de novos elementos e sem representatividade; 3 ) Com adição parcial de novos elementos paisagísticos, com representatividade; 4) Com adição parcial de novos elementos paisagísticos, mas sem representatividade; 5) Com adição total ou completa de novos elementos.

Também foi analisado nos desenhos dos alunos, antes e depois da trilha, a expressão dos mesmos quanto à relação homem e natureza, sendo ela harmônica ou desarmônica. Buscou-se identificar a percepção do aluno no que diz respeito a se o homem estava inserido no ambiente natural e de que maneira ele aparecia no cenário. Foram agrupados nas seguintes categorias: 1) Os desenhos que trouxeram a imagem do próprio homem inserido no meio, que muitas vezes estava tomando banho na Fonte ou então no espaço exterior a ela.; 2) Os desenhos que representaram a presença do homem no espaço natural numa relação utilitária, através das figuras de casa, comércio e lixo, o qual este último representa a relação negativa do homem com o meio ambiente; e 3) Os desenhos que excluíram o homem do meio natural.

O método de análise de conteúdo foi utilizado na perspectiva segundo Bardin (1997) e Derdyk (1989), que tem por finalidade a manifestação das mensagens, levando em consideração o seu conteúdo e a sua expressão; além disso, utilizaram-se indicadores que irão permitir a dedução sobre a realidade implícita à mensagem, através do raciocínio.

\section{A análise da percepção dos estudantes}

Os desenhos sobre a Fonte de água de Pureza foram produzidos livremente pelos alunos antes e depois da realização da trilha, após orientações prévias. Foram analisados os desenhos dos alunos nas turmas do $1^{\circ}$ ano (11 desenhos), $2^{\circ}$ ano (11 desenhos), $3^{\circ}$ ano (10 desenhos), $4^{\circ}$ ano (17 desenhos) e $5^{\circ}$ ano (13 desenhos).

As perguntas que guiaram as entrevistas realizadas antes da trilha foram: Qual a importância da Fonte para você e sua família aqui em Pureza? Você acha que a Fonte de Pureza é bem cuidada pelos moradores da cidade e pelos visitantes? Por quê?

Após a realização da trilha perguntou-se: O que você aprendeu hoje sobre a Fonte de Pureza que ainda não sabia? O que você mais gostou na visita da trilha na Fonte? O que você acha que pode fazer para ajudar na preservação da Fonte? 


\section{A trilha interpretativa}

Foi elaborado um roteiro para guiar a trilha, composto por quatro pontos, incluindo a nascente do rio, a vegetação do entorno, a piscina para banho e um trecho do curso do rio, após a nascente. A trilha foi elaborada considerando os conceitos de preservação de nascente, vegetação no entorno, doenças de veiculação hídrica e poluição, os quais foram apresentados por meio de uma conversa a partir de questionamentos que evidenciam o envolvimento e a aproximação do aluno tanto na atividade quanto no ambiente, além de nortearem as discussões, conforme sintetizado no Quadro 01. O roteiro completo foi disponibilizado para a escola, para que futuramente possam desenvolver essa atividade novamente com outros alunos.

O deslocamento ao local de realização da trilha ocorreu por meio de ônibus escolar, cedido pela Secretaria Municipal de Educação, Cultura e Desportos, Prefeitura Municipal de Pureza - RN, no qual os alunos foram acompanhados pelas professoras das respectivas turmas, direção e equipe da escola, além da equipe da UFRN que esteve na organização da atividade.

Quadro 1

Roteiro da Trilha interpretativa na Fonte de Pureza/RN.

\begin{tabular}{|c|c|c|c|}
\hline Ponto & em & Objetivo & Questionamentos \\
\hline $\begin{array}{l}\text { Em frente à Fonte } \\
\text { de Pureza, onde } \\
\text { se utilizam de suas } \\
\text { águas para lazer, } \\
\text { além de captação } \\
\text { e distribuição para } \\
\text { o consumo da } \\
\text { população. }\end{array}$ & $\begin{array}{l}\text { Fonte de Pureza/RN. } \\
\text { Imagem: Layana Morais }\end{array}$ & $\begin{array}{l}\text { Abordar como a água } \\
\text { é importante para a } \\
\text { vida, explicar como a } \\
\text { água chega ao solo e } \\
\text { como rio nasce, com } \\
\text { isso, remetendo ao } \\
\text { ciclo da água. }\end{array}$ & $\begin{array}{l}\text { Porque esse espaço é } \\
\text { chamado de nascente? } \\
\text { Vocês já ouviram falar } \\
\text { se essa água sempre } \\
\text { foi nessa altura ou se } \\
\text { mudou com o tempo? } \\
\text { Como essa água chegou } \\
\text { até lá embaixo? Qual a } \\
\text { importância dessa água } \\
\text { para a cidade? }\end{array}$ \\
\hline $\begin{array}{l}\text { Árvores ao redor } \\
\text { da Fonte, as } \\
\text { quais compõem } \\
\text { remanescentes } \\
\text { do Bioma Mata } \\
\text { Atlântica. }\end{array}$ & Árvores ao redor da Fonte. & $\begin{array}{l}\text { Explicar sobre a } \\
\text { assimilação de água } \\
\text { pelos vegetais e como } \\
\text { esse processo, que } \\
\text { envolve absorção e } \\
\text { transpiração, contribui } \\
\text { para o ciclo da água. }\end{array}$ & $\begin{array}{l}\text { Qual a relação das } \\
\text { plantas com a água da } \\
\text { nascente? } \\
\text { Qual a importância de } \\
\text { ter plantas ao redor da } \\
\text { Fonte? } \\
\text { O acontece se não houver } \\
\text { plantas nesse espaço? }\end{array}$ \\
\hline
\end{tabular}




\begin{tabular}{|c|c|c|c|}
\hline $\begin{array}{l}\text { Piscina após a } \\
\text { Fonte, onde se } \\
\text { utilizam de suas } \\
\text { águas para lazer. }\end{array}$ & $\begin{array}{l}\text { Piscina após a Fonte. } \\
\text { Imagem: Layana Morais }\end{array}$ & $\begin{array}{l}\text { Explicar sobre as } \\
\text { doenças deveiculação } \\
\text { hídrica e os cuidados } \\
\text { necessários com a } \\
\text { utilização da água } \\
\text { para consumo e lazer, } \\
\text { devido aos impactos } \\
\text { ao a mbiente e } \\
\text { saúde. }\end{array}$ & $\begin{array}{l}\text { Vocês já viram algum } \\
\text { caramujo por aqui? } \\
\text { Vocês ou algum familiar } \\
\text { já teve a doença barriga } \\
\text { d'água? E alguma dor de } \\
\text { barriga? Como algumas } \\
\text { doenças acontecem } \\
\text { através da água? Quem } \\
\text { é responsável por isso? }\end{array}$ \\
\hline $\begin{array}{l}\text { Trecho do rio, } \\
\text { após a Fonte, } \\
\text { onde se visualiza o } \\
\text { segmento do rio. }\end{array}$ & $\begin{array}{l}\text { Ponte após a piscina. } \\
\text { Imagem: Layana Morais }\end{array}$ & $\begin{array}{l}\text { Abordaranecessidade } \\
\text { de se ter um uso } \\
\text { mais sustentável da } \\
\text { água e a importância } \\
\text { da conservação da } \\
\text { Fonte de Pureza } \\
\text { para o equilíbrio no } \\
\text { ambiente, realizando } \\
\text { um fechamento da } \\
\text { atividade. }\end{array}$ & $\begin{array}{l}\text { Quais as diferenças que } \\
\text { percebemos desde a } \\
\text { nascente até aqui? } \\
\text { Quem é responsável por } \\
\text { cuidar e não poluir o rio? } \\
\text { Se eu poluir em um ponto } \\
\text { do rio afeta a outros ao } \\
\text { longo do seu percurso? }\end{array}$ \\
\hline
\end{tabular}

\section{RESULTADOS E DISCUSSÃO}

A percepção dos alunos dos $2^{\circ}, 3^{\circ}$ e $4^{\circ}$ anos (24\%) relacionaram de forma mais completa os elementos físico-químicos, fauna e flora em seus desenhos, com 18\%, 20\% e $65 \%$ respectivamente, destacando-se o $4^{\circ}$ ano, em que os alunos trouxeram em seus desenhos um conhecimento prévio abrangendo mais elementos do ambiente (FIG. 02).

Percebeu-se que 44\% dos alunos não incluíram os animais no ambiente, relacionando em seus desenhos somente os elementos físico-químicos e flora, representada pelos $1^{\circ}$, $2^{\circ}, 3^{\circ}, 4^{\circ}$ e $5^{\circ}$ anos, com $27 \%, 27 \%, 80 \%, 24 \%$ e $69 \%$ respectivamente. Destacaram-se os alunos dos $3^{\circ}$ e $5^{\circ}$ anos, que apresentaram maiores percentagens e, para os demais, poderia haver desconhecimento dessa relação ou mesmo não associação dos componentes do ecossistema aquático no geral.

Já os alunos que não incluíram as plantas no ambiente, equivalem a $21 \%$ e relacionaram os elementos físico-químicos e fauna seus desenhos, representados pelos $1^{\circ}$, $2^{\circ}$ e $3^{\circ}$ anos, com $64 \%, 45 \%$ e $8 \%$ respectivamente, o que pode sugerir baixa percepção de alguns alunos em relação às plantas como integrantes do meio ambiente.

Os alunos que trouxeram apenas elementos físico-químicos em seus desenhos corresponderam a um total de $11 \%$, representados pelos $1^{\circ}, 2^{\circ}, 4^{\circ}$ e $5^{\circ}$ anos, com apenas $9 \%, 9 \%, 12 \%$ e $23 \%$ respectivamente, demonstrando uma percepção incompleta de alguns alunos quanto aos elementos constituintes no ambiente, pois não fizeram relação com flora e fauna. 


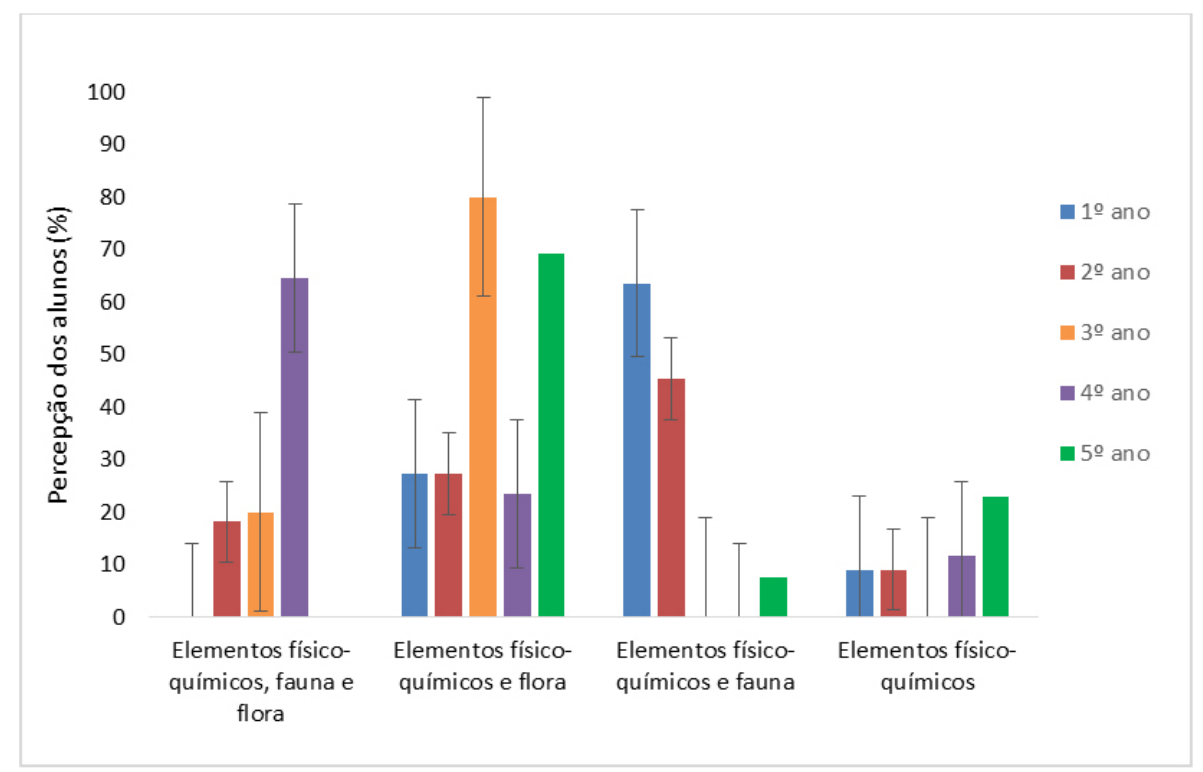

Figura 2. Percepção dos alunos sobre a nascente expressa nos desenhos antes da trilha interpretativa na Fonte de Pureza/RN.

A percepção final dos alunos sobre a nascente. foi significativa, comparativamente com a percepção dos mesmos no primeiro desenho, sendo possível identificar expressões que remetem ao conhecimento construído no decorrer da trilha interpretativa, conforme Figura 03.

Em relação à percepção dos alunos após a trilha, 18\% dos alunos não apresentaram novos elementos paisagísticos em seus desenhos, mas havia certa representatividade. Os alunos das turmas do $1^{\circ}, 2^{\circ} 3^{\circ}, 4^{\circ}$ e $5^{\circ}$ anos, mostraram um percentual de $9 \%, 9 \%, 20 \%$, $35 \%$ e $8 \%$ respectivamente. Com isso, pode-se perceber que os alunos dos $3^{\circ}$ e $4^{\circ}$ anos, se destacaram dos demais, por conseguirem explorar mais elementos paisagísticos em seus desenhos, mesmo sem haver inclusão de novos elementos, eles contextualizaram devidamente o cenário trabalhado em suas produções.

Observou-se que $15 \%$ dos alunos não adicionaram novos elementos paisagísticos em seus desenhos após a trilha e nem havia representatividade, representados pelos $1^{\circ}, 2^{\circ}$, $3^{\circ}, 4^{\circ}$ e $5^{\circ}$ anos e percentual de $9 \%, 9 \%, 20 \%, 24 \%$ e $8 \%$, respectivamente. Os alunos dos $3^{\circ}$ e $4^{\circ}$ anos se destacaram dos demais e demonstram que, nessas turmas, alguns alunos tiveram mais dificuldade de explorar em seus desenhos os conhecimentos trabalhados na trilha.

Alguns alunos adicionaram parcialmente novos elementos paisagísticos em seus desenhos após a trilha e havia representatividade neles, equivalendo a $44 \%$ dos alunos dentre os $1^{\circ}, 2^{\circ}, 3^{\circ}, 4^{\circ}$ e $5^{\circ}$ anos, com percentual de $55 \%, 36 \%, 30 \%, 35 \%$ e $62 \%$, 
respectivamente. Têm-se resultados bastante positivos, comparativamente com os demais, correlacionando com os novos conhecimentos construídos, porque os elementos paisagísticos encontravam-se contextualizados, representando devidamente o cenário no desenho. Pode-se perceber que os $1^{\circ}$ e $5^{\circ}$ anos se destacaram, demonstrando que independente da faixa etária, teve-se um bom proveito em como os alunos dessas turmas puderam explorar mais satisfatoriamente em suas produções de desenhos.

Quanto aos alunos que adicionaram parcialmente novos elementos paisagísticos em seus desenhos após a trilha, mas sem haver representatividade, tem-se $16 \%$ dos alunos dentre os $1^{\circ}, 2^{\circ}, 3^{\circ}, 4^{\circ}$ e $5^{\circ}$ anos, com percentual de $18 \%, 27 \%, 20 \%, 6^{\circ}$ e $15 \%$ respectivamente, o que sugere o nível de dificuldade dos alunos de explorar em seus desenhos um cenário contextualizado, interligado e que representa o espaço real. $\mathrm{O} 4^{\circ}$ ano apresenta o menor valor, indicando que, os alunos desta turma foram os que tiveram menor dificuldade em representar os conhecimentos construídos nos seus desenhos, comparados às demais turmas. E o $2^{\circ}$ ano, apresenta o maior valor, o que demonstra que os alunos desta turma foram os que tiveram maior dificuldade de explorar suas produções, em abranger um cenário representativo em seus desenhos, comparados às demais turmas.

Somente $8 \%$ dos alunos apresentaram em seus desenhos a percepção correspondente à expressão de adição total ou completa de novos elementos paisagísticos em seus desenhos após a trilha, representados pelos $1^{\circ}, 2^{\circ}, 3^{\circ}$ e $5^{\circ}$ anos, com percentual de $8 \%$, $18 \%, 10 \%$ e $8 \%$ respectivamente, o que indica certa dificuldade dos alunos de explorar em seus desenhos os conhecimentos recém trabalhados. Os alunos dos $1^{\circ}$ e $5^{\circ}$ anos apontam para uma maior dificuldade, podendo ser atribuído à alguma dificuldade na associação dos conteúdos ou interesse e emocional dos alunos na atividade no dia de sua realização.

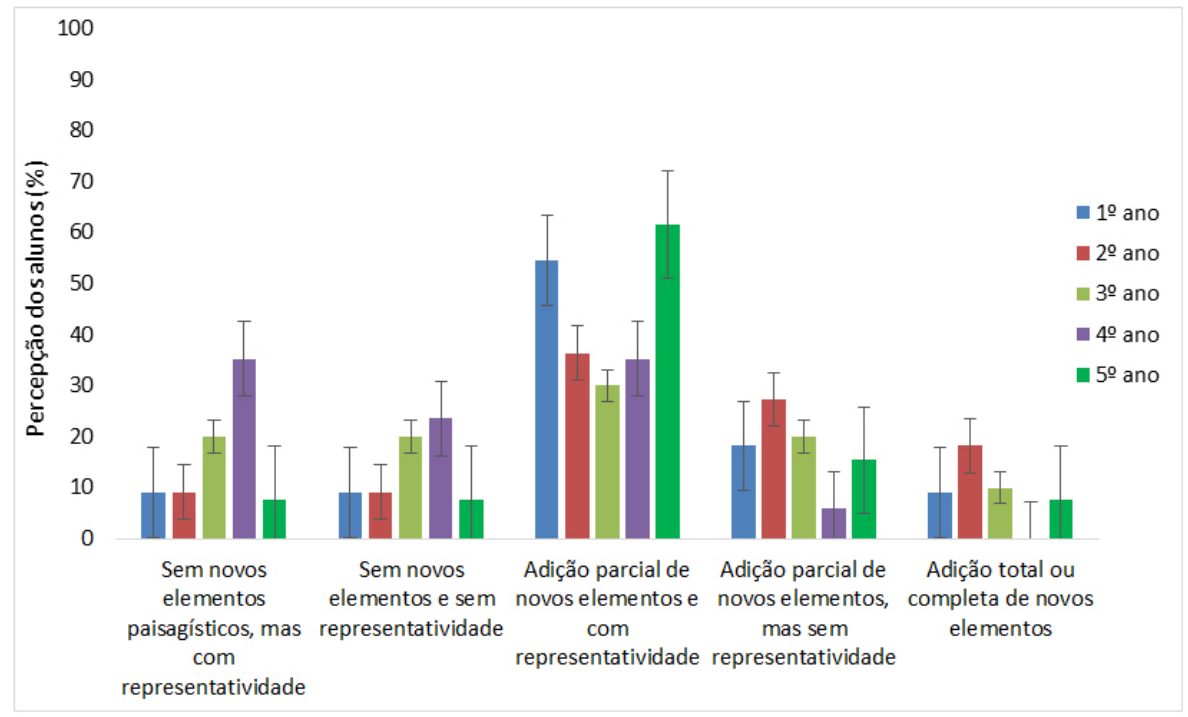

Figura 3. Percepção dos alunos sobre a nascente expressa nos desenhos após a trilha interpretativa na Fonte de Pureza/RN. 
Quanto à existência ou não da relação homem e natureza, representado na FIG. 04. seja ela harmônica ou desarmônica, pode-se perceber que nos $1^{\circ}, 2^{\circ}$ e $4^{\circ}$ anos houve uma diminuição da representação do homem como parte do meio nos desenhos dos alunos após a realização da trilha e no $4^{\circ}$ ano, passou a zero. Já nos $3^{\circ}$ e $5^{\circ}$ anos, não modificou, continuou exatamente o mesmo valor.

Observou-se que no $1^{\circ}$ ano nenhum dos alunos apresentou os elementos que representam a percepção da natureza utilitária em seus desenhos, antes e depois da trilha. Nos $2^{\circ}, 4^{\circ}$ e $5^{\circ}$ anos, aumentou o percentual de alunos que a representam, após a realização da trilha e no $5^{\circ}$ ano, que não tinha nenhum no desenho de antes da trilha, passou a apresentar no depois. Já no $3^{\circ}$ ano, houve diminuição.

Em relação à percepção dos alunos da natureza intocada, pode-se perceber um aumento no percentual de alunos dos $1^{\circ}, 2^{\circ}$ e $3^{\circ}$ anos representando essa percepção em seus desenhos após a realização da trilha, já os $4^{\circ}$ e $5^{\circ}$ anos, uma diminuição. Ela traz uma realidade importante a se discutir, pois os resultados demonstram como, normalmente, $o$ homem enxerga a natureza, quando a questão é proteção. Diegues (2000) discute sobre o mito da natureza intocada, no que diz respeito ao homem muitas vezes achar que, para a conservação dos recursos ambientais, é preciso se excluir do meio natural.

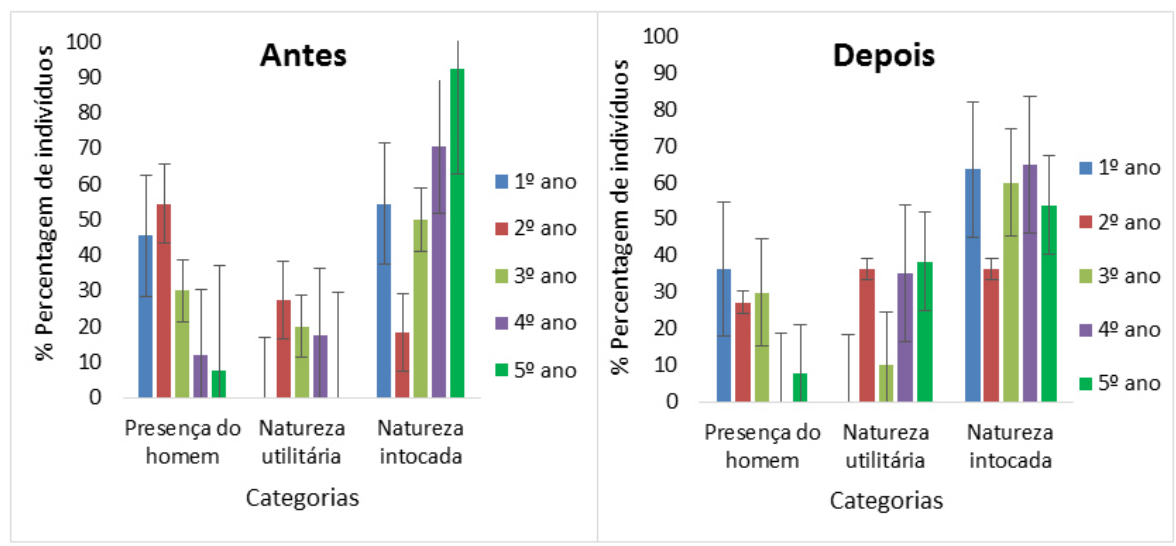

Figura 4. Percepção dos alunos sobre a relação Homem e Natureza expressa nos desenhos antes e depois da trilha interpretativa na Fonte de Pureza/RN.

A análise da percepção dos alunos na entrevista, demonstrou que eles passaram a enxergar de forma mais sensível a Fonte, quanto à sua importância e utilização depois da realização da trilha e que fizeram uma relação mais completa, considerando o conhecimento construído sobre a Fonte (Figura 05).

Ao serem questionados, antes da trilha, sobre qual a importância da Fonte para suas vidas e de suas famílias em Pureza, observou-se que $35 \%$ das respostas dos alunos mencionaram ao uso para recreação. Destacam-se os alunos do $1^{\circ}$ e $3^{\circ}$ anos, com $80 \%$ e $50 \%$ respectivamente, os quais demonstram a grande tendência de se atribuir 
essa utilização à Fonte, centralizada no homem e no seu lazer. Essa mesma ideia foi representada alunos do $5^{\circ}$ ano, com $25 \%$. Já os alunos dos $2^{\circ}$ e $4^{\circ}$ anos não atribuíram essa importância à Fonte.

No que concerne ao uso doméstico da Fonte, representado por 35\% dos alunos, os resultados expressam outra forte tendência de atribuição da sua importância, ao benefício humano, conferindo ao homem certa dependência das águas da Fonte de Pureza para suas atividades diárias, representada por $100 \%$ do $4^{\circ}$ ano e $50 \%$ do $5^{\circ}$ ano, os quais associariam à realidade local. Somente $25 \%$ dos alunos do $3^{\circ}$ ano apresentaram essa mesma tendência. E nenhum dos alunos dos $1^{\circ}$ e $2^{\circ}$ anos, representaram essa percepção em seus discursos.

Já para a compreensão da atribuição da importância da Fonte para a natureza, homem e animais, apenas $10 \%$ dos alunos representaram essa visão. Os $1^{\circ}$ e $5^{\circ}$ anos, com $20 \%$ e $25 \%$ respectivamente e nenhum dos alunos dos $2^{\circ}, 3^{\circ}$ e $4^{\circ}$ anos representaram essa percepção em seus discursos, o que demonstra uma fraca e, até mesmo inexistente, comparada com as demais respostas, associação da harmonia da Fonte com o meio ambiente e o homem fazendo parte dele.

Alguns alunos apenas remeteram à poluição, sem responderem necessariamente à pergunta sobre a importância da Fonte de Pureza para suas vidas e de suas famílias, correspondendo a $20 \%$ dos alunos. Representados pelos $2^{\circ}$ e $3^{\circ}$ anos, $100 \%$ e $25 \%$ respectivamente, eles expressaram menção de incômodo ao se tratar da Fonte, assemelhando-se como expressão de um protesto diante da realidade encontrada e, em seus discursos, enfatizaram que as pessoas vão ao local e poluem, mas que não se deve ter essa atitude.

Quando perguntou-se aos alunos, antes da trilha, se a Fonte era, ou não, bem cuidada pelos moradores da cidade e visitantes, $25 \%$ dos alunos responderam que sim, sendo representados pelos $1^{\circ}$ e $4^{\circ}$ anos, com $80 \%$ e $25 \%$ respectivamente. Esse baixo percentual demonstra uma opinião crítica em relação ao comportamento das pessoas diante do meio ambiente e, localmente, da Fonte de Pureza.

Já $75 \%$ dos alunos que responderam não, representados pelos $1^{\circ}, 2^{\circ}, 3^{\circ}, 4^{\circ}$ e $5^{\circ}$ anos, $\operatorname{com} 20 \%, 100 \%, 100 \%, 75 \%$ e $100 \%$ respectivamente, expressaram um alto índice de respostas negativas quanto ao cuidado das pessoas com a Fonte e, ainda, os alunos acrescentaram em seus discursos que já haviam visto pessoas poluindo no local e que tem pessoas que não ligam para o meio ambiente.

Ao perguntar, após a trilha, sobre o que os alunos aprenderam na atividade o qual ainda não sabiam, 35\% dos alunos expressaram a percepção quanto à ocorrência e modo de vida dos animais aquáticos, sendo representados pelos alunos dos $1^{\circ}$ e $2^{\circ}$ anos, com $40 \%$ e $100 \%$ respectivamente, os quais destacaram mais nos seus discursos quanto ao que se trabalhou dos animais aquáticos e o fato de ter encontrado alguns no local, como peixes, caramujos e patos, despertou ainda mais o interesse dos alunos. Somente $25 \%$ dos alunos dos $3^{\circ}$ e $5^{\circ}$ anos, cada, apresentaram essa mesma percepção. E no $4^{\circ}$, nenhum dos alunos atribuíram esse aprendizado em seus discursos. 
Quanto à importância das plantas para a nascente, somente $15 \%$ dos alunos, tiveram essa percepção. Apenas os alunos dos $4^{\circ}$ e $5^{\circ}$ anos, com $25 \%$ e $50 \%$ respectivamente, fizeram essa associação em seus discursos, demonstrando que poucos alunos têm a percepção ou conhecimento sobre a relação direta da contribuição da vegetação para a manutenção da nascente.

Relacionado aos aspectos físicos da água e ciclo da água, que corresponde a $30 \%$ dos alunos, tem-se percentagens significativas nos $3^{\circ}$ e $4^{\circ}$ anos, com $50 \%$ e $75 \%$ respectivamente, o que demonstra a percepção de como os processos físico-químicos estão interligados, expressa por alguns alunos em seus discursos, contudo, nos $2^{\circ}$ e $5^{\circ}$ anos, não foi feita essa associação.

Sobre a utilização da água, poluição e doenças, somente $20 \%$ dos alunos, tiveram essa percepção, incluindo apenas $1^{\circ}, 3^{\circ}$ e $5^{\circ}$ anos, com $40 \%, 25 \%$ e $25 \%$ respectivamente, as quais podem sugerir que talvez já seja de conhecimento popular entre alguns alunos, que muitas vezes eles ouvem essas relações dos adultos.

Quando foi perguntado aos alunos sobre o que mais gostaram na visita da trilha na Fonte e, $50 \%$ deles demonstraram a percepção no que se refere a encontrar e conhecer sobre os animais aquáticos, sendo representados pelos alunos dos $1^{\circ}, 2^{\circ}, 3^{\circ}, 4^{\circ}$ e $5^{\circ}$ anos, com $60 \%, 100 \%, 25 \%, 25 \%$ e $50 \%$ respectivamente, demonstrando que os alunos atribuíram muito significado ao contato com o meio e ao encontro com alguns dos organismos que compõem o ecossistema aquático, além de conhecerem mais sobre seu modo de vida.

Quanto a oportunidade de conhecer sobre nascentes e relação com o contexto local, incluindo o ecossistema aquático no geral e o curso do rio, somente $30 \%$ dos alunos tiveram essa percepção, os quais foram representados pelos alunos dos $3^{\circ}, 4^{\circ} \mathrm{e}$ $5^{\circ}$ anos, com $50 \%$ cada. Percebe-se que, conforme a faixa etária aumenta, a percepção desse contexto da nascente torna-se um assunto mais atrativo, o qual eles conseguiram associar e expressar em seus discursos.

Quanto a atribuir maior satisfação em conhecer sobre as doenças e ciclo de infecção, somente $10 \%$ dos alunos apresentaram essa percepção em seus discursos, representados pelos alunos dos $1^{\circ}$ e $4^{\circ}$ anos, com $20 \%$ e $25 \%$ respectivamente, o que pode sugerir que essa temática não foi a de maior interesse de discussão entre os alunos, mesmo que tenha a sua importância.

No que se refere à saída do âmbito escolar e socialização, incluindo o envolvimento com as atividades propostas, $10 \%$ dos alunos demonstraram essa percepção, correspondendo aos alunos de $1^{\circ}$ e $3^{\circ}$ anos, com $20 \%$ e $25 \%$ respectivamente, o que demostra que alguns alunos atribuíram significado ao simples ato de sair, de andar no ônibus escolar, de realizar atividades dinâmicas e de se socializar, evidenciando a importância de atividades como essas para os alunos e professores. 


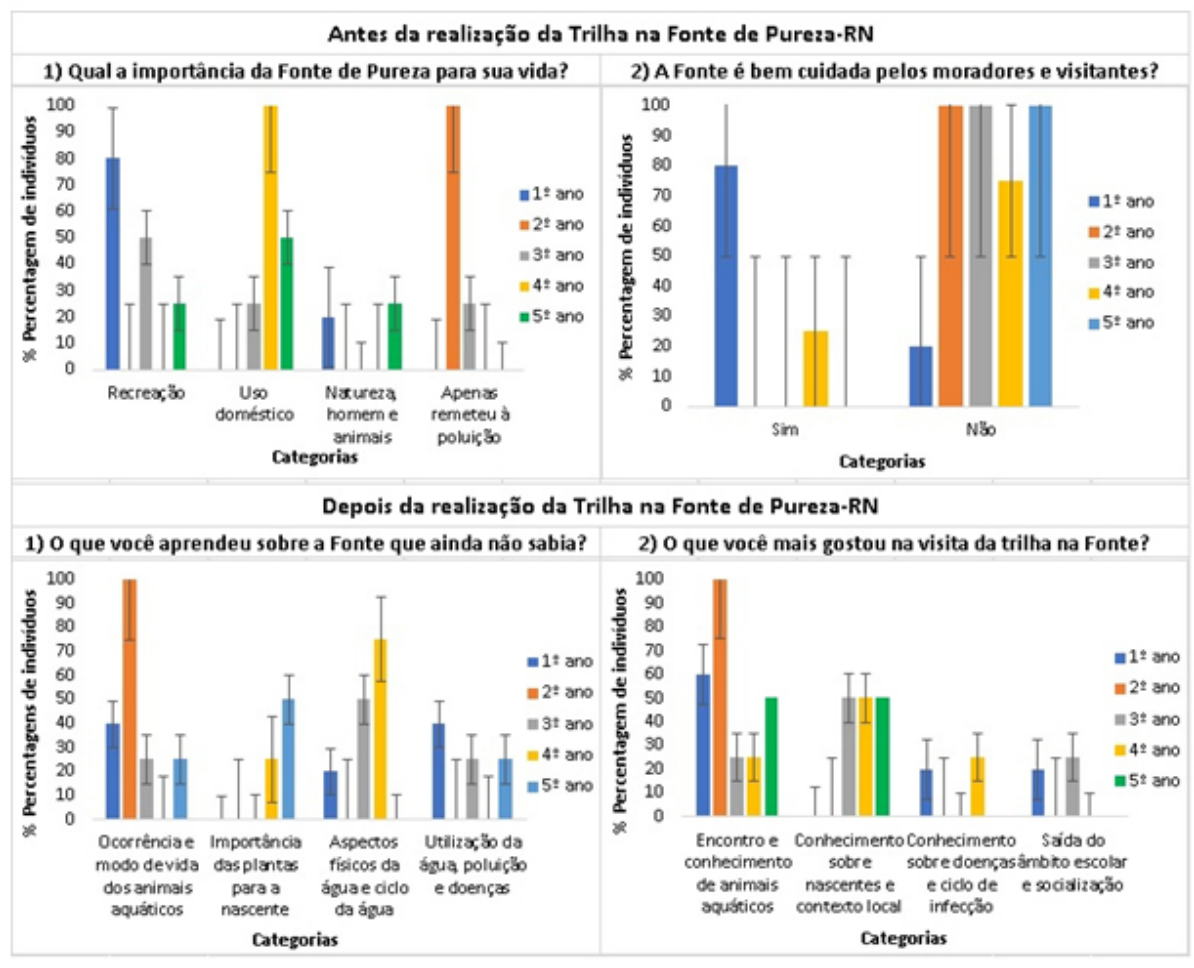

Figura 5. Percepção dos alunos sobre a importância e usos da nascente expressa na entrevista realizada antes e depois da trilha interpretativa na Fonte de Pureza/RN.

Durante a trilha, as impressões que ficaram foi que os alunos estavam interessados e participativos. Os questionamentos nortearam as discussões e auxiliaram na construção do conhecimento científico; o foco era a participação do aluno na sua própria construção, conforme abordado por Souza e Dourado (2015), que discutem sobre algumas metodologias que vêm sendo desenvolvidas por professores, os quais visam uma aprendizagem significativa, nas quais o aluno é o próprio protagonista do seu aprendizado. Silva, Bigi \& Kalhil (2009) afirmam, a respeito do que atividades educacionais fora do âmbito escolar podem proporcionar aos professores e alunos:

Os espaços não formais oportunizam aos alunos a possibilidade de interação de ver, tocar e aprender numa relação homem-natureza. Assim, entendemos que os espaços não formais oferecem subsídios para o professor no ensino de ciências, emergindo como desafio para tornar o ensino mais prazeroso e ampliando o interesse dos alunos. (Silva; Bigi; Kalhil, 2009, p.88) 


\section{CONCLUSÕES}

A trilha interpretativa em um ambiente natural, como a nascente visitada, representa uma importante ferramenta na sensibilização ambiental, pois o contato com a natureza proporciona a integração e a consciência de que fazemos parte dela, incentivando a uma cidadania responsável.

Ao analisarmos a percepção dos alunos expressa nos desenhos e entrevistas, foi possível perceber o significativo potencial didático da realização da trilha interpretativa, pois os novos conhecimentos construídos refletiram nas suas produções de desenhos e discursos, de maneira a relacioná-los com mais coerência, abrangência e, ainda, demonstrando mais sensibilidade com o meio ambiente.

\section{REFERÊNCIAS}

Bacci, D. D. L. C. et al. (2009) Educando nas águas do Pirajuçara-uma proposta de Educação Ambiental. Revista de Cultura e Extensão USP, 2, 41-53.

Bardin, L. (1997) Análise de Conteúdo. Lisboa: Edições 70.

Brasil. Ministério da Saúde. Sistema Nacional de Vigilância em saúde. (2011) Relatório de situação: Rio Grande do Norte. 5. ed. Brasília, DF. 35 p.

Brasil. Secretaria de Educação Fundamental. (1997) Parâmetros curriculares nacionais: introdução aos parâmetros curriculares nacionais. Brasília: MEC/SEF. 126p.

Derdyk, E. (1989) Formas de pensar o desenho: desenvolvimento do grafismo infantil. São Paulo: Scipione.

Diegues, A. C. S. (2000) O mito moderno da natureza intocada. 3.ed. São Paulo: Hucitec Núcleo de Apoio à Pesquisa sobre Populações Humanas e Áreas Úmidas Brasileiras, USP. Bibliografia: p.161. ISBN 85-271-0345-1

Felippe, M. F. (2009) Caracterização e tipologia de nascentes em unidades de conservação de Belo Horizonte/MG com base em variáveis geomorfológicas, hidrológicas e ambientais. 2009. 277 f. Dissertação (Mestrado em Geografia) - Universidade Federal de Minas Gerais, Belo Horizonte.

Gohm, M. G. (1999) Educação não formal e cultura política. Impactos sobre o associativismo do terceiro setor. São Paulo, Cortez.

Ikemoto, S. M. (2008) As trilhas interpretativas e sua relevância para promoção da conservação: Trilha do Jequitibá, Parque Estadual dos Três Picos (PETP), RJ. 2008. 170 f. Dissertação (Mestrado em Ciência Ambiental), Universidade Federal Fluminense, Niterói.

Jacobucci, D. F. C. (2008) Contribuições dos espaços não formais de educação para a formação da cultura científica. Em extensão, Uberlândia, v.7.

Laville, C.; Dionne, J. (1999) A construção do saber: manual de metodologia da pesquisa em ciências humanas. Porto Alegre: ArtMed.

Lima, S. T. (1998) Trilhas Interpretativas: A aventura de conhecer a Paisagem. Cadernos Paisagem, Rio Claro, UNESP, 3, 39-44. 
Moreira, M. A. (2005) Aprendizaje Significativo Crítico Indivisa, Boletín de Estúdios e Investigación, 6, 83-101.

Praxedes, G. C. (2009) A utilização de espaços de educação não formal por professores de Biologia de Natal (RN). 128f. 2009. Universidade Federal do Rio Grande do Norte. (Dissertação de Mestrado Profissionalizante). Pós-Graduação em Ensino de Ciências Naturais e Matemática: Natal: PPGECNM/CCET.

Silva, R. E. V.; Bigi, M. F.; Kalhil, J. B. (2009) Parques de Manaus: uma proposta de Ensino de Biologia em espaços não formais. Novas Tendências Pedagógicas: proposta alternativa no ensino de ciências. Curitiba: CRV, 1, 87-94.

Souza, S. C.; Dourado, L. (2015) Aprendizagem baseada em problemas (ABP): um método de aprendizagem inovador para o ensino educativo. Holos, 5. 